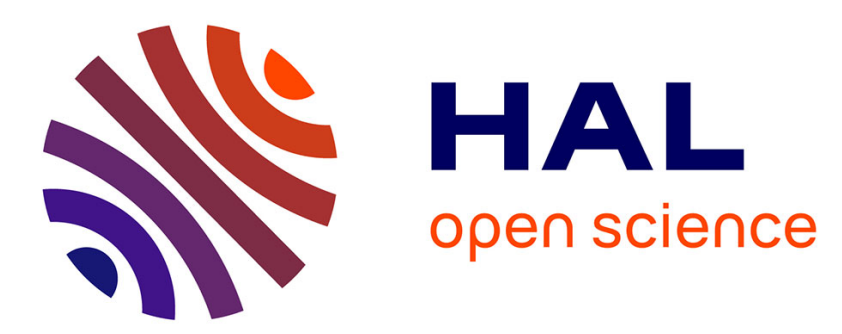

\title{
XANES Study of Ce and Mo Containing Conversion Coatings on Aluminium
}

\author{
J. Wan, G. Thompson, T. Ng, K. Lu, C. Smith
}

\section{To cite this version:}

J. Wan, G. Thompson, T. Ng, K. Lu, C. Smith. XANES Study of Ce and Mo Containing Conversion Coatings on Aluminium. Journal de Physique IV Proceedings, 1997, 7 (C2), pp.C2-1183-C2-1184. 10.1051/jp4:19972184 . jpa-00255253

\section{HAL Id: jpa-00255253 https://hal.science/jpa-00255253}

Submitted on 1 Jan 1997

HAL is a multi-disciplinary open access archive for the deposit and dissemination of scientific research documents, whether they are published or not. The documents may come from teaching and research institutions in France or abroad, or from public or private research centers.
L'archive ouverte pluridisciplinaire HAL, est destinée au dépôt et à la diffusion de documents scientifiques de niveau recherche, publiés ou non, émanant des établissements d'enseignement et de recherche français ou étrangers, des laboratoires publics ou privés. 


\title{
XANES Study of Ce and Mo Containing Conversion Coatings on Aluminium
}

\author{
J. Wan, G.E. Thompson, T.K. Ng, K.Q. Lu* and C.J.E. Smith** \\ Corrosion and Protection Center, UMIST, Manchester M60 IQD, UK \\ * Institute of Physics, Chinese Academy of Sciences, Beijing, 100080, China \\ ** Defence Research Agency, Farnborough, Hants, GU14 6TD, UK
}

\begin{abstract}
Ce-Mo conversion coatings on superpure aluminium have been examined using XANES and analytical TEM to study the coating development over the electropolished surface. Ce species are predominantly in the $\mathrm{Ce}^{3+}$ state in the coating, resulting from the various steps of the process, and $\mathrm{Mo}$ is in the $\mathrm{Mo}^{6+}$ state. After immersion in $\mathrm{NaCl}$ solution, Ce and $\mathrm{Mo}$ species leach from the coating. Conversion coating formation develops a hydrated film with cerium species incorporated; final anodic polarisation in $\mathrm{MoO}_{4}^{2-}$ solution results in Mo species in the hydrated film. Corrosion inhibition is attributed to the coating acting as a barrier layer to environmental access to the aluminium substrate and reduced cathodic activity.
\end{abstract}

\section{INTRODUCTION}

The Ce-Mo process has been developed to protect aluminium alloy substrates[1]. The improved behaviour of the coated substrate in $\mathrm{NaCl}$ solution, including high pitting potential, low passive current density and high pitting resistance, is revealed from anodic and cathodic polarisation, and electrochemical impedance spectroscopy. However understanding of the coating formation mechanism and the manner in which protection is afforded is limited due to lack of precise characterisation of the coating. Consequently the present study has investigated the valence states of incorporated cerium and molybdenum species in the coatings formed on superpure aluminium, together with morphological observations of the coatings and the electrochemical behaviour of the treated aluminium, enabling insight into the mechanism of coating formation from consideration of the individual steps in the process and the protection afforded.

\section{EXPERIMENTAL}

Electropolished $99.99 \%$ aluminium sheets were treated by the Ce-Mo process, which involved 2 hours immersion in boiling $10 \mathrm{mM} \mathrm{Ce}\left(\mathrm{NO}_{3}\right)_{3}$ solution followed by a further 2 hours immersion in boiling $5 \mathrm{mM} \mathrm{CeCl}$ solution and, finally, potentiostatic anodic polarisation for 2 hours in $0.1 \mathrm{M} \mathrm{Na}_{2} \mathrm{MoO}_{4}$ solution at room temperature. The valence states of $\mathrm{Mo}$ and Ce species associated with the coating formed by the Ce-Mo process were evaluated by XANES analyses. Both Ce $\mathrm{L}_{m}$ and Mo $\mathrm{K}$ edge XANES spectra were measured for freshly treated specimens and others which had been immersed in $0.5 \mathrm{NaCl}$ solution for 15 and 30 days. XANES measurements were made on beamline 7C at the Photon Factory, Japan, in the fluorescence mode in air using a harmonically rejecting Si(111) two-crystal monochromator. Two ionization chambers were used to measure incident photon $\left(I_{0}\right)$ and fluorescence $\left(I_{f}\right)$ intensities. Ultramicrotomy allowed TEM examination.

\section{RESULTS AND INTERPRETATION}

$\mathrm{Ce} \mathrm{L}_{\text {III }}$ edge standard spectra were determined for model compounds $\mathrm{CeCl}_{3} 7 \mathrm{H}_{2} \mathrm{O}$ and $\mathrm{CeO}_{2}$, providing references for $\mathrm{Ce}^{3+}$ and $\mathrm{Ce}^{4+-}$ species respectively (Fig. 1 , curves $\mathrm{b}$ and a); for the Mo $\mathrm{K}$ edge spectra, Mo metal foil, $\mathrm{Na}_{2} \mathrm{MoO}_{4}$ and $\mathrm{MoO}_{2}$ compounds provided reference values for $\mathrm{Mo}^{\circ}, \mathrm{Mo}^{6+}$ and $\mathrm{Mo}^{4+}$ species respectively (Fig.2, curves a, b and c). Examination of the Ce $\mathrm{L}_{\mathrm{m}}{ }^{-}$ edge XANES spectra of the standards reveals a single peak at the absorption edge for $\mathrm{Ce}^{3+}$ species, and a twin peak for $\mathrm{Ce}^{4+}$, providing information for recognition and discrimination of the $\mathrm{Ce}^{3+}$ and $\mathrm{Ce}^{4+}$ valence states. Further, with increasing $\mathrm{Ce}^{4+}$ content, the height of the second peak increases proportionally, giving information on the constitution of the film from observation of the edge shape [2]. By comparison of the shape of the spectra with that of the standards, the valence states of molybdenum species can also be identified since, for $\mathrm{MoO}_{4}{ }^{2-}$, there is a small peak at the half height of the edge and, although the spectra of $\mathrm{Mo}$ foil and $\mathrm{MoO}_{2}$ have a clear edge, different structures above the edge are evident. Further, the edge position for Mo foil (20003 eV) is $5 \mathrm{eV}$ lower than that of $\mathrm{MoO}_{2}$.

Ce and Mo edge XANES spectra of the coatings, formed in each step of the Ce-Mo process, are shown in Figs. 1 and 2 respectively, with the insets revealing sections of the corresponding coatings. The first hydrothermal treatment reveals a typical hydrated film, formed by reaction of aluminium with boiling water, comprising an inner textured region and an outer platelet layer (Fig. la). The metal/film interface appears relatively flat. The second treatment gives a similar coating appearance. For the final coating from the Ce-Mo process, at selected areas, a thin layer, about 10-20 nm thick, of dark deposits of $\mathrm{Ce}$ rich species, is evident above an inner compact layer (Fig.1b). Mo species were found throughout the coating 
by EDX. The metal/film interface is of scalloped appearance, resulting from the preferred dissolution of the aluminium during the treatment. Generally, the coating morphology is similar to that from the hydrothermal treatment (Fig. 1c).

The valence states of Ce and Mo species, obtained from XANES, for the coatings are summarised as follows: (a) after immersion in boiling $\mathrm{Ce}\left(\mathrm{NO}_{3}\right)_{3}$ solution for 2 hours, the $\mathrm{Ce}$ species are present as a mixture of mainly $\mathrm{Ce}^{3+}$ with a small contribution from $\mathrm{Ce}^{4+}$ species (Fig. 1, curve c); (b) after the second step, $2 \mathrm{~h}$ immersion in boiling $5 \mathrm{mM} \mathrm{CeCl}_{3}$ solution, the $\mathrm{Ce}$ edge height is 6 times that ofhe first step, suggesting increased $\mathrm{Ce}$ species in the film, with similar proportions of $\mathrm{Ce}^{3+}$ and $\mathrm{Ce}^{4+}$ species to that from the first step (Fig.1, curve d); (c) the final step of the Ce-Mo process, i.e. anodic polarisation in $\mathrm{Na}_{2} \mathrm{MoO}_{4}$ for 2 hours results in an overall decrease of Ce species, by about $50 \%$, with no Ce ${ }^{4+}$ contribution to the spectrum (Fig.1, curve e); (d) compared with the standard Mo K edge spectra, the Mo species associated with the film are in the Mo ${ }^{6+}$ valence state (Fig. 2, c); (e) immersion of the treated specimens in $0.5 \mathrm{M} \mathrm{NaCl}$ solution for 15 and 30 days dramatically decreases both $\mathrm{Ce}$ and $\mathrm{Mo}$ species, i.e. up to $95 \%$ for $\mathrm{Ce}$ and $70 \%$ for Mo. The Mo species remaining in the $\mathrm{Mo}^{6+}$ state (Figs.2, $\mathrm{d}$ and e). The XANES result thus suggests leaching of $\mathrm{Ce}$ and $\mathrm{Mo}$ species into $\mathrm{NaCl}$ solution during immersion.

Coating development during hydrothermal treatment is similar to hydrated film growth on aluminium in boiling water, with transformation of the original air-formed film to variously hydrated alumina including pseudoboechmite. Oxygen reduction occurs at cathodic sites with local increase of $\mathrm{pH}$. With $\mathrm{Ce}$ ions, $\mathrm{Ce}(\mathrm{OH})_{3}$ precipitates locally, with small amounts oxidized to $\mathrm{Ce}(\mathrm{OH})_{4}$. Thus, a hydrated oxide layer (with probably trapped Ce species) forms over the macroscopic surface, with $\mathrm{Ce}$ hydroxide deposited at cathodic sites. Anodic polarization of the previously hydrothermally treated aluminium substrate in molybdate solution heals flaw sites in the hydrated film by anodic alumina formation, where the substrate anodizes, generating acidic conditions and leading to dissolution of some $\mathrm{Ce}(\mathrm{OH})_{3}$ and precipitation of $\mathrm{MoO}_{3}$ gel-like material. $\mathrm{Ce}(\mathrm{OH})_{4}$ may also dissolve or be reduced due to the strong oxidizing properties of $\mathrm{Ce}^{4+}$ ions in acid environment. Elsewhere, where there are no flaws in the hydrated film from the hydrothermal treatments, the hydrated layer is little affected by the final anodic polarization.

Electrochemical measurements reveal that the Ce-Mo treated aluminium has an increased pitting potential and reduced anodic and cathodic current densities. This arises from (i) the film developed by the anodic treatment in the presence of a hydrated oxide acts as an insulating barrier, limiting exposure of aluminium to the environment; (ii) incorporated molybdenum species provide a potential self-healing ability when the the film is damaged and (iii) cathodic activity is restricted due to deposited cerium compounds.

\section{CONCLUSIONS}

XANES has been shown to be a powful tool in chemical states recognition, allowing mechanisms of protective coating formation on aluminium to be advanced.

\section{References}

[1] F.Mansfeld, Y.Wang, S.H.Lin, L.Kwiatkowski, ICC, 219, Houston, U.S.A., 1993.

[2] J.Wan, G.E.Thompson, K.Lu, C.J.E.Smith, submitted to this conference.

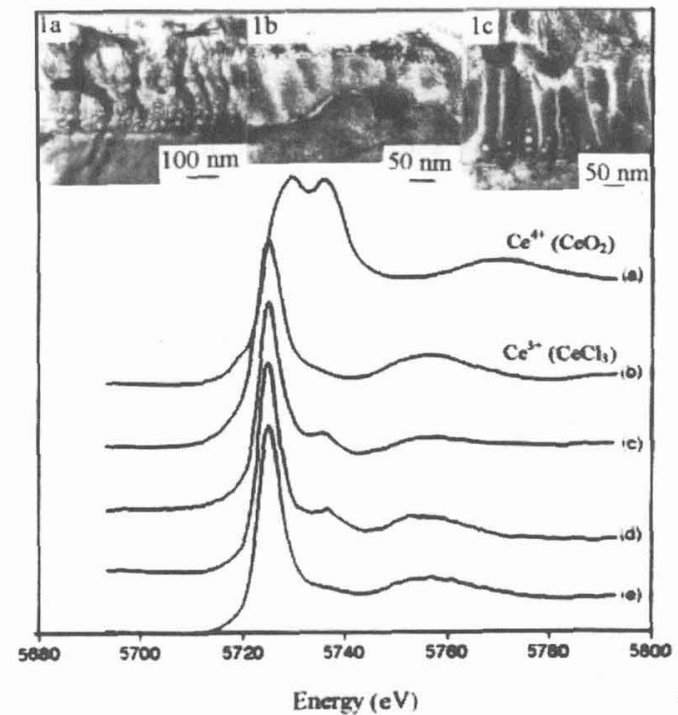

Fig. 1 Ce $\mathrm{L}_{\text {III }}$ edge XANES spectra of standards and coated Al.

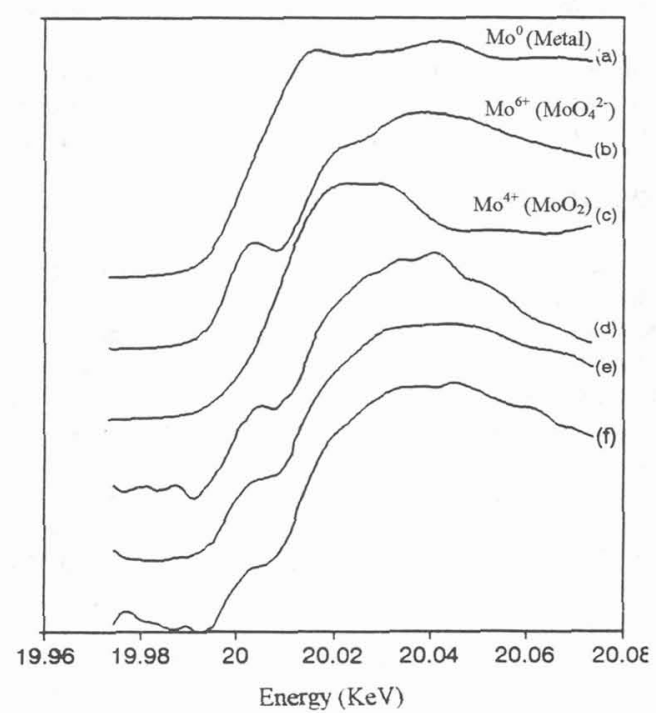

Fig. 2 Mo K edge XANES spectra of standards and coated Al. 